\title{
Available web-based teaching resources for health care professionals on screening for oral cancer
}

\author{
Pablo Varela-Centelles ${ }^{1,2}$, Angel Insua ${ }^{1}$, Juan M. Seoane-Romero ${ }^{1}$, Saman Warnakulasuriya ${ }^{3,4}$, Alexander \\ Rapidis ${ }^{5}$, Pedro Diz ${ }^{1}$, Juan Seoane ${ }^{1}$
}

\author{
${ }^{1}$ OMEQUI Research Group. School of Medicine and Dentristry. Santiago de Compostela University. 15782 Santiago de Com- \\ postela (A Coruña). Spain \\ ${ }^{2}$ EOXI Lugo. Galician Health Service. Praza Ferrol 11. 27001 Lugo. Spain \\ ${ }^{3}$ Oral Medicine, King's College, London, UK \\ ${ }^{4}$ WHO Collaborating Centre for Oral Cancer, London, UK \\ ${ }^{5}$ Greek Anticancer Institute, Saint Savvas Hospital, Athens, Greece
}

Correspondence: Cantón Grande 5 Apt. $1^{\circ}$ E. 15003

A Coruña. Spain

juanmanuel.seoane@usc.es

Received: 11/05/2014

Accepted: 02/10/2014
Varela-Centelles P, Insua A, Seoane-Romero JM, Warnakulasuriya S, Rapidis A, Diz P, Seoane J. Available web-based teaching resources for health care professionals on screening for oral cancer. Med Oral Patol Oral Cir Bucal. 2015 Mar 1;20 (2):e144-9.

http://www.medicinaoral.com/medoralfree01/v20i2/medoralv20i2p144.pdf

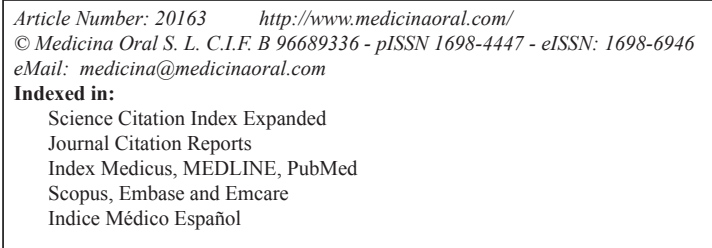

\begin{abstract}
Objectives: To identify websites with adequate information on oral cancer screening for healthcare professionals (HCPs) and to assess both their quality and contents.

Study Design: Websites were identified using Google and HON medical professional search engines using the terms "screening for oral cancer". The first 100 sites retrieved by each engine were analysed using the DISCERN questionnaire (reliability), the V instrument (contents on oral cancer) and further by the Flesch-Kinkaid Reading Grade Level and the Flesch Reading Ease (readability).

Results: The overall rating showed minimal shortcomings in the quality of the information in the websites. The coverage and correctness of information on "visual examination" was rated as fair/good, whereas updating of contents resulted very variable (eg: $81 \%$ for visual examination and $18.2 \%$ for molecular biomarkers). These results permitted to rank the websites housing relevant information for oral cancer. Top ranking websites were affiliated to the Oral Cancer Foundation (USA), WHO Collaborating Centre for oral cancer (UK) whose webpage is entitled "Oral Cancer Education and Research", and the Clinical Guidelines maintained by the British Columbia Cancer Agency (Canada) and the British Dental Association (UK) respectively.

Conclusions: There are web-based, HCP-addressed, resources on screening for oral cancer housing heterogeneous information both in quality and contents. The use of specific evaluation tools permits the selection of reliable websites on this topic with a potential to improve the existing educational gaps among HCPs.
\end{abstract}

Key words: Oral cancer, early diagnosis, screening, secondary prevention, internet, teaching resources, continuous education. 


\section{Introduction}

Internet search for medical or health-related issues is very frequent, and cancer-related topics account for a substantial proportion of these searches even when significant discrepancies in terms of quality of the oncological information available on-line have been reported $(1,2)$.

A study unveiled that on-line cancer-related contents seem to help physician-patient communication, favour shared decision-making, and facilitate the setting of realistic expectations (3).

The issue of web-based information on precancer (potentially malignant disorders) has also been studied $(4,5)$, and both topics (precancer and cancer) have scored uneven accuracy levels (6) and low quality standards (7), but these shortcomings do not seem to discourage patients. Even the reported distrust of the information provided on-line is perceived as a minor reason for not using webbased resources to find oral cancer information (8).

Healthcare professionals' (HCP) knowledge on oral cancer is widely variable and frequently suboptimal (9). Physicians achieve important parts of their knowledge -up to $80 \%$ - informally on the Internet (10), particularly those from middle-income countries (11), mostly seeking information on diagnostic and laboratory tests. Unreliability of the web-based information is a serious threat for Internet use in clinical information seeking (12). No investigation assessing the quality of available web-based oral cancer information for HCPs could be retrieved.

Thus, the aim of this study was to identify websites with free-access in the Internet with adequate information on oral cancer screening for HCPs and to assess both their quality and contents.

\section{Material and Methods}

-Searching strategy

Websites were identified in November 2013 by means of 2 search engines: Google (www.google.com) and HON medical professional (www.hon.ch/med.html), using the terms "screening for oral cancer" and the English language for the interface and operative system, without predetermined location or filters. The websites were displayed (10 sites per page), accessed, and saved in a DVD for analysis.

The first 100 consecutive results, as sorted by the search engines, were considered for the study. Exclusion criteria were: irrelevant contents, exclusively commercial information, patient-targeted sites, duplicated websites, forums and discussion groups, non-operative sites, and password-protected webpages.

-Evaluation procedures

The selected websites were categorised by specialisation (totally or partially related to oral cancer screening) and affiliation (non-profit organisation, commercial, university/medical centre, government) (6). We also recorded whether the website was awarded the Health On the Net
(HON) seal: a non-profit foundation to guide lay people and HCPs to reliable health-related information on the Internet. The HON code of conduct for medical and health websites ensures the criteria of authoritative, complementarity, privacy, attribution, justifiability, transparency, financial disclosure and advertising policy.

-Quality assessment

Quality was rated using the DISCERN questionnaire, a valid and reliable tool where each question $(n=16)$ is scored in a 1 (poor) to 5 (good) Likert scale. Questions 1 to 8 address the reliability of the publication (trust) as a source of information (13), and includes a final item on the overall rating of the publication which was considered an outcome of this investigation. The review process was independently undertaken by two observers (IA \& VP); in case of disagreement, a third reviewer (coordinator) was involved.

The information in each site was assessed using the oral cancer websites content review instrument V (14), specifically designed for analysing oral cancer contents, which is available at www.dentalinformatics.org/tools/ oralcancer/.

The study was restricted to diagnostic information, which was analysed in terms of presence (yes/no), coverage of information, correctness of information (both in a 4-point Likert scale: good, fair, poor, not available (N/A). Each answer choice carried a number of points (good=3; fair=2; poor=1; N/A=0) (15).

The retrieved information and its correctness were evaluated according to existing evidence $(15,16)$, and the scores (good coverture and correctness achieved for the visual examination item in the analysis of contents) were used to identify websites housing relevant information.

-Readability assessment

The Flesch-Kinkaid Reading Grade Level (FKRGL) and the Flesch Reading Ease (FRES) were used to assess legibility of the selected websites $(17,18)$. These score systems are well validated for assessing the readability of English-written information (19). An online calculator program (www.readabilityformulas.com) was employed for this purpose, prior determination of its accuracy using the following readability formulas: $\mathrm{FRE}=206.835-(1.015 \mathrm{x}$ Average number of words per sentence) - (84.6 x Average number of syllables per word $)$ FKRGL $=(0.39 \times$ Average number of words per sentence $)+(11.8 \times$ Average number of syllables per word) -15.59 .

-Statistical analysis

Data were coded, recorded and analysed using a statistical package (SPSS Inc, Chicago, IL, USA). A descriptive study was performed and both normality and variance homogeneity were analysed using the KolmogorovSmirnov and Levene tests respectively. The independent samples t-test was used for comparing means. The confidence level chosen for all tests was $95 \%$. 


\section{Results}

Google search yielded 402,000 results in 0.18 seconds whereas HON returned 5,520 hits in 0.26 seconds. Out of the first 100 consecutive sites considered by each search engine, 83 google-search sites and $89 \mathrm{HON}-$ search sites did not meet the inclusion criteria and were excluded from the study. Another 6 sites were recognised by both browsers. Finally, 22 websites were included in the study (Fig. 1).

Chosen webpages mostly bore the seal of either government $(n=10 ; 45.5 \%)$ or non-profit organization $(n=9 ; 40.9 \%)$ affiliations, with a low grade of specialization, and only 5 $(22.7 \%)$ were exclusively related to oral cancer screening. No significant differences between search engines could be disclosed in terms of contents, quality and legibility of the information (Table 1).

The mean score for the overall rating of the publications using the DISCERN scale was $4.18 \pm 1.05$, so minimal shortcomings in the quality of the information in the websites considered in the study can be assumed (Fig. 2).

The contents assessment in terms of coverage and correctness is displayed in figure 3 , where information on

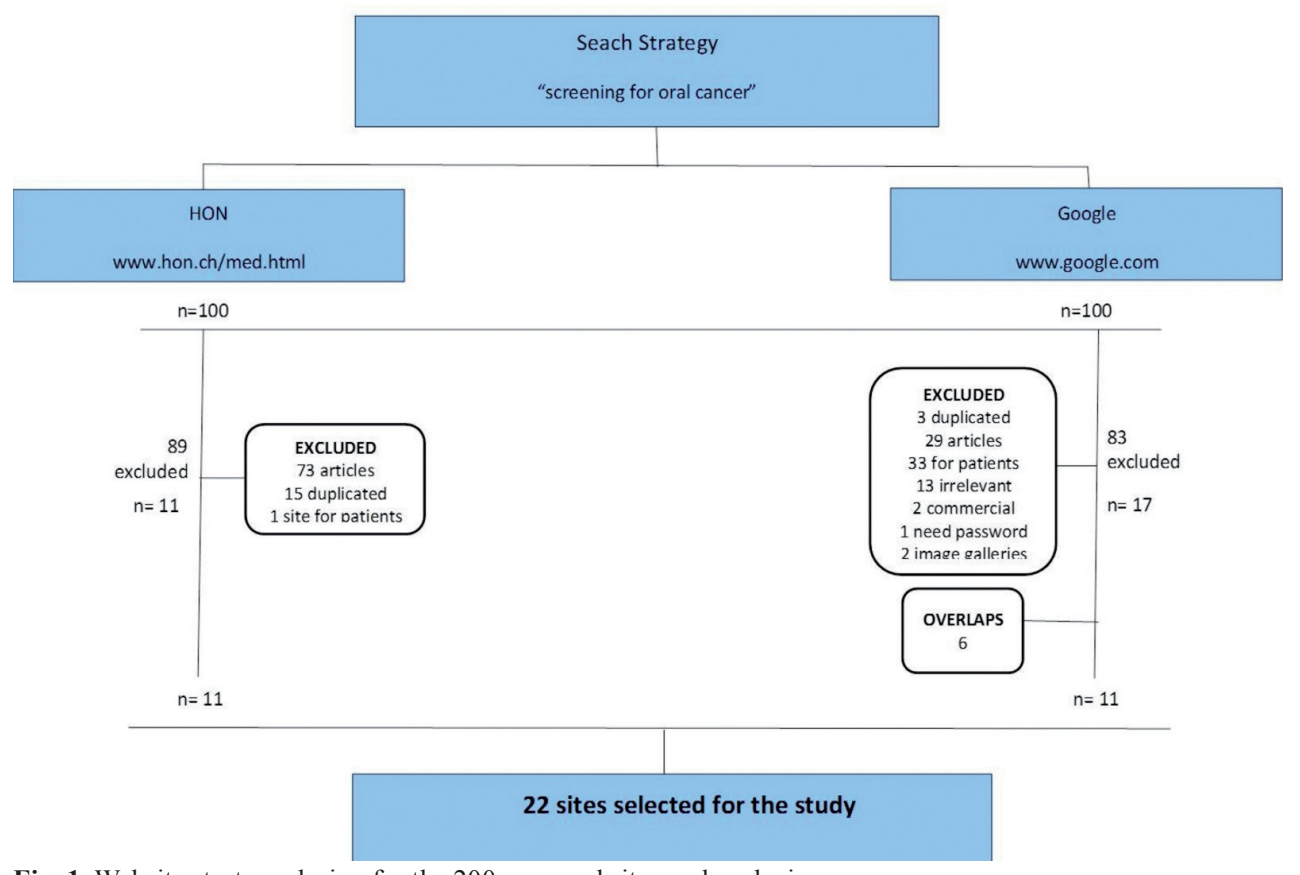

Fig. 1. Website strategy design for the 200 accessed sites and exclusions.

Table 1. Data on contents analysis, quality and readability of the selected web-sites (Google vs HON search engine).

\begin{tabular}{|l|c|c|c|c|}
\hline & $\begin{array}{c}\text { Google } \\
\mathbf{N}=\mathbf{1 7}\end{array}$ & $\begin{array}{c}\text { HON } \\
\mathbf{N}=\mathbf{1 1}\end{array}$ & \\
\hline Variable & $\mathbf{X} \pm$ SD & $\mathbf{X} \pm$ SD & $\mathbf{X}_{\mathrm{i}}-\mathbf{X}_{\mathbf{j}} \mathbf{( 9 5 \% \mathbf { C } )}$ & $\boldsymbol{p}$-value \\
\hline $\begin{array}{l}\text { DISCERN } \\
\text { Overall rating }\end{array}$ & $4.23 \pm 1.14$ & $4.09 \pm 1.22$ & $0.14(-0.79,1.07)$ & 0.75 \\
\hline $\begin{array}{l}\text { Visual examination } \\
\text { Coverage score }\end{array}$ & $2.29 \pm 0.68$ & $2.00 \pm 1.00$ & $0.29(-0.35,094)$ & 0.36 \\
\hline $\begin{array}{l}\text { Visual examination } \\
\text { Correcteness score }\end{array}$ & $2.64 \pm 0.60$ & $2.36 \pm 1.12$ & $0.28(-0.38,0.95)$ & 0.79 \\
\hline $\begin{array}{l}\text { New diagnostic aids } \\
\text { Coverage score }\end{array}$ & $1.76 \pm 1.20$ & $1.90 \pm 1.13$ & $0.14(-1.07,0.79)$ & 0.75 \\
\hline $\begin{array}{l}\text { New diagnostic aids } \\
\text { Correctness score }\end{array}$ & $1.94 \pm 1.29$ & $2.18 \pm 1.16$ & $0.24(-1.23,0.75)$ & 0.62 \\
\hline $\begin{array}{l}\text { FRES } \\
\text { Score }\end{array}$ & $36.02 \pm 12.37$ & $34.73 \pm 14.06$ & $1.29(-9.08,11.67)$ & 0.80 \\
\hline $\begin{array}{l}\text { FKRGL } \\
\text { Score }\end{array}$ & $13.05 \pm 2.43$ & $13.83 \pm 2.62$ & $0.77(-2.77,1.21)$ & 0.43 \\
\hline
\end{tabular}




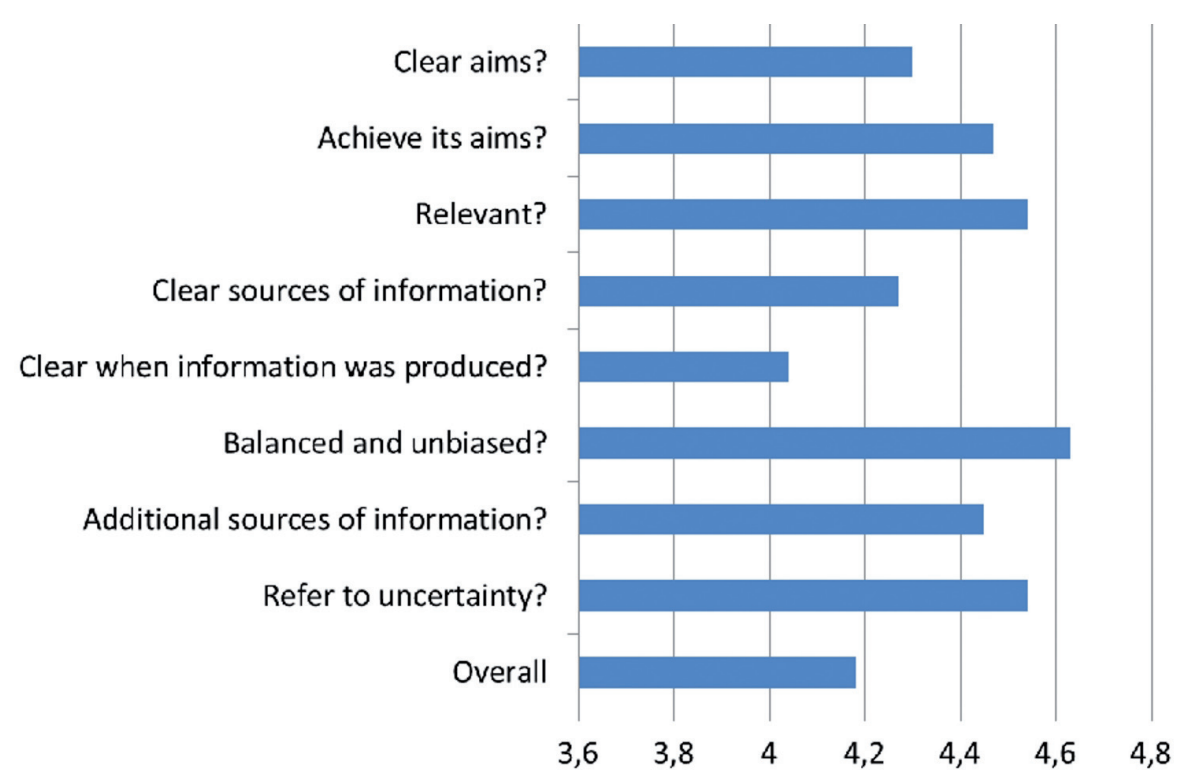

Fig. 2. Mean quality ratings across the 22 included sites, using the validated DISCERN instrument.

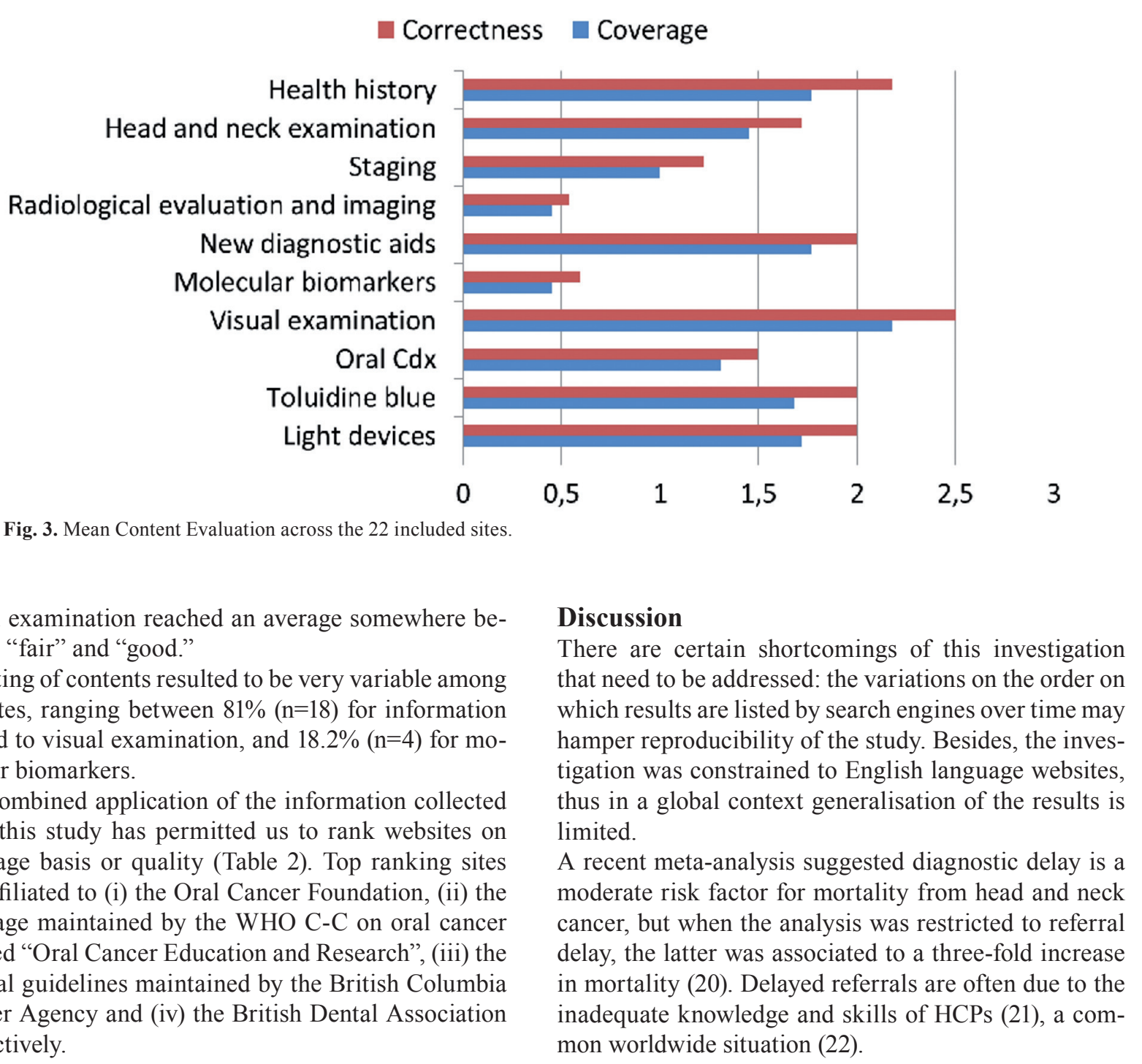


Table 2. Features of the top 9 websites by Content and Quality rating.

\begin{tabular}{|c|c|c|c|c|c|c|c|c|}
\hline Website URL & Affiliation & Site type & $\begin{array}{l}\text { Traffic in } \\
\text { past 30d }\end{array}$ & $\begin{array}{c}\text { Flesch } \\
\text { Readin } \\
\text { g }\end{array}$ & $\begin{array}{l}\text { Flesch- } \\
\text { Kinkaid }\end{array}$ & $\begin{array}{l}\text { Grade } \\
\text { level }\end{array}$ & Discern & $\begin{array}{l}\text { HON } \\
\text { Code }\end{array}$ \\
\hline www.bccancer.bc.ca & BCCA & G & 32.600 & 13,2 & 16,3 & College & 4,8 & YES \\
\hline www.bda.org & $\mathrm{BDA}$ & NP & 29.400 & 39,8 & 14,6 & College & 4,8 & $\mathrm{NO}$ \\
\hline www.oralcancerfoundation.com & $\mathrm{OCF}$ & NP & N/A & 46,3 & 12,3 & 12 & 4,6 & YES \\
\hline$\frac{\text { www.ocEdr.com }}{\text { (WHO C-C on Oral Cancer) }}$ & ocEdr & NP & N/A & 21,6 & 17,7 & $\begin{array}{l}\text { College } \\
\text { and } \\
\text { above }\end{array}$ & 4,6 & $\mathrm{NO}$ \\
\hline http://www.medscape.com/ & WebMD & $\mathrm{C}$ & 3.890 .600 & 38,5 & 12,4 & 12 & 4,5 & $\mathrm{NO}$ \\
\hline www.ada.org & $\mathrm{ADA}$ & $\mathrm{G}$ & 363.800 & 12,9 & 16,9 & College & 4,4 & NO \\
\hline http://www.hta.ac.uk & NHS & G & N/A & 28,3 & 14,8 & College & 4,3 & NO \\
\hline www.guideline.gov & AHRQ & G & 119.100 & 7,7 & 20 & College & 3,9 & $\mathrm{NO}$ \\
\hline www.sixstepscreening.org & * & NP & N/A & 39,8 & 10,9 & 11 & 3,1 & NO \\
\hline
\end{tabular}

Affiliation; BCCA. British Columbia Cancer Agency; BDA. British Dental Association; OCF. Oral cancer foundation; ocEdr. Oral Cancer Education and Research; WebMD Health Professional Network; ADA. American Dental Association; NHS. National institute for Health Research; AHRQ. Agency for Healthcare Research and Quality; * Private page.

Site type; C: commercial; NP: non-profit; U/MC: University/Medical Centre; G: Governmental

Traffic data from www.trafficestimate.com; N/A (not avaliable)

Lack of knowledge and experience are recognised as the main barriers to the provision of routine oral cancer examinations (21). Medical websites seem to fulfil the requirements for an ideal source of medical information to minimise this problem. Lack of knowledge, issues with information technology or online sources and limited search skills have been suggested as obstacles for Internet use by HCPs (11). Conversely, new technologies like mobile equipment availability and new apps for practitioners would allow learning, teaching and practising anywhere, anytime (23).

Patients frequently use the Internet to agree or not on consenting to surgical decision making (24), and headneck cancer patients usually seek information on treatment and secondary effects (managing changes in swallowing and speaking), and on how to maintain their health after treatment $(8,25,26)$. Physicians tend to use web-based resources to ease clinical decision making (24), mostly related to diagnostic work-up and therapy (26). However, both the presence of irrelevant contents and their poor reliability are paramount barriers to using the Internet for information seeking (12).

Previous reports have described a poor quality of the patient-addressed information about lichen planus, oral leukoplakia, and oral and head and neck cancers (4-7). On the other hand, our study indicates that the overall quality rate of the information about screening for oral cancer in HCP-addressed websites reached a high standard on application of the DISCERN instrument, particularly the sites listed in the first four places, which achieved an score higher than 4.5, showing minimal shortcomings.

Despite DISCERN is a validated, widely used tool for determining the reliability of a publication, it was not designed for assessing the accuracy of the scientific contents displayed within the site $(6,14)$.

Dental care professionals should remain vigilant for signs of oral cancer whilst performing routine oral examination in practice (15) because visual and tactile examination may result in early detection of oral carcinomas (stages I-II) $(14,16)$; this being the reason to employ the "adequate coverage and correctness" of the information on this topic to identify relevant HCPaddressed websites.

It is worth mentioning that although ancillary tests for oral cancer screening (eg.: toloudine blue or commercial devices based upon tissue reflectance or autofluorescence) have not been adequately tested for primary care use (16), the websites selected for this study offer an adequate information on this topic (Fig. 2). Only molecular biomarkers and transepithelial cytology (Oral $\mathrm{Cdx}$ ) were poorly covered by these webpages.

To the best of our knowledge, no previous study has assessed the readability of oral cancer websites; defined as the reading skills an individual must possess to understand a written text (17). By extracting FRES for our selection of websites, we found the contents "difficult to read", probably due to the technical nature of the information displayed. These contents would also be difficult for patients to understand, as the reading grade level calculated for these websites is well above what is recommended for health-related materials for patients (6th or below) (27).

WHO has recommended involving oral-health professionals in detection and early diagnosis of oral cancer (28). Even though increasing knowledge and skills for oral cancer screening is traditionally considered as a chief educational objective related to secondary pre- 
vention, there are still gaps of knowledge among HCPs on this topic (21) which may condition effectiveness of screening for oral cancer. In this sense, web-based oral cancer resources may contribute to improve the current situation particularly by creating international cooperation networks and electronic websites housing worldwide information for training on this topic (29). Based on an EU initiative on lifelong learning our group has been commissioned to deliver a web based learning programme on the early detection of oral cancer for European Dentists. This can be accessed via www.oralcancerldv.org.

\section{Conclusion}

Our study demonstrated that there are web-based, HCP-addressed, resources on screening for oral cancer housing heterogeneous information both in quality and contents. The use of specific evaluation tools permits the selection of reliable websites on this topic with a potential to help reducing the existing educational gaps among HCPs.

\section{References}

1. Lawrentschuk N, Sasges D, Tasevski R, Abouassaly R, Scott AM, Davis ID. Oncology health information quality on the Internet: a multilingual evaluation. Ann Surg Oncol. 2012;19:706-13.

2. Ferreira D, Carreira H, Silva S, Lunet N. Assessment of the contents related to screening on Portuguese language websites providing information on breast and prostate cancer. Cad Saude Publica. 2013;29:2163-76.

3. Eysenbach $\mathrm{G}$. The impact of the Internet on cancer outcomes. CA Cancer J Clin. 2003;53:356-71.

4. López-Jornet P, Camacho-Alonso F. The quality of internet information relating to oral leukoplakia. Med Oral Patol Oral Cir Bucal. 2010;15:e727-31.

5. López-Jornet P, Camacho-Alonso F. The quality of patient-orientated Internet information on oral lichen planus: a pilot study. J Eval Clin Pract. 2010;16:883-6.

6. Ni Riordain R, McCreary C. Head and neck cancer information on the internet: type, accuracy and content. Oral Oncol. 2009;45:675-7.

7. López-Jornet P, Camacho-Alonso F. The quality of Internet sites providing information relating to oral cancer. Oral Oncol. 2009; 45:e95-8.

8. Rogers SN, Rozek A, Aleyaasin N, Promod P, Lowe D. Internet use among head and neck cancer survivors in the North West of England. Br J Oral Maxillofac Surg. 2012;50:208-14.

9. Maybury C, Horowitz AM, Yan AF, Green KM, Wang MQ. Maryland dentists' knowledge of oral cancer prevention and early detection. J Calif Dent Assoc. 2012;40:341-50.

10. Schmidt T. Informal education of medical doctors on the Internet. Stud Health Technol Inform. 2013;190:92-4.

11. Gavino AI, Ho BL, Wee PA, Marcelo AB, Fontelo P. Informationseeking trends of medical professionals and students from middleincome countries: a focus on the Philippines. Health Info Libr J. 2013;30:303-17.

12. Bernard E, Arnould M, Saint-Lary O, Duhot D, Hebbrecht G. Internet use for information seeking in clinical practice: a cross-sectional survey among French general practitioners. Int J Med Inform. 2012;81:493-9.

13. Charnock D, Shepperd S. Learning to DISCERN online: applying an appraisal tool to health websites in a workshop setting. Health Educ Res. 2004;19:440-6.
14. Irwin JY, Thyvalikakath T, Spallek H, Wali T, Kerr AR, Schleyer T. English and Spanish oral cancer information on the internet: a pilot surface quality and content evaluation of oral cancer web sites. J Public Health Dent. 2011;71:106-16.

15. Walsh T, Liu JL, Brocklehurst P, Glenny AM, Lingen M, Kerr AR, et al. Clinical assessment to screen for the detection of oral cavity cancer and potentially malignant disorders in apparently healthy adults. Cochrane Database Syst Rev. 2013;11:CD010173.

16. Rethman MP, Carpenter W, Cohen EE, Epstein J, Evans CA, Flaitz CM, et al. Evidence-based clinical recommendations regarding screening for oral squamous cell carcinomas. J Am Dent Assoc. 2010;141:509-20.

17. Badarudeen S, Sabharwal S. Assessing readability of patient education materials: current role in orthopaedics. Clin Orthop Relat Res. 2010;468:2572-80.

18. Livas C, Delli K, Ren Y. Quality evaluation of the available Internet information regarding pain during orthodontic treatment. Angle Orthod. 2013;83:500-6.

19. Pothier L. Patient-orientated web sites on laryngectomy: is their information readable?. Eur J Cancer (Engl). 2009;18:594-7.

20. Seoane J, Takkouche B, Varela-Centelles P, Tomás I, Seoane Romero JM. Impact of delay in diagnosis on survival to head and neck carcinomas: a systematic review with meta-analysis. Clin Otolaryngol. 2012;37:99-106.

21. Gómez I, Warnakulasuriya S, Varela-Centelles PI, López-Jornet $\mathrm{P}$, Suárez-Cunqueiro M, Diz-Dios $\mathrm{P}$, et al. Is early diagnosis of oral cancer a feasible objective? Who is to blame for diagnostic delay? Oral Dis. 2010;16:333-42.

22. Hertrampf K, Wiltfang J, Koller M, Klosa K, Wenz HJ. Dentists' perspectives on oral cancer: a survey in Northern Germany and a comparison with international data. Eur J Cancer Prev. 2010;19:14452.

23. Khatoon B, Hill KB, Walmsley AD. Can we learn, teach and practise dentistry anywhere, anytime?. Br Dent J. 2013;215:345-7. 24. Couper MP, Singer E, Levin CA, Fowler FJ, Fagerlin A, ZikmundFisher BJ. Use of the Internet and ratings of information sources for medical decisions: results from the DECISIONS survey. Med Decis Making. 2010;30:106S-114S.

25. Fang CY, Longacre ML, Manne SL, Ridge JA, Lango MN, Burtness BA. Informational Needs of Head and Neck Cancer Patients. Health Technol (Berl). 2012;2:57-62.

26. Davies K, Harrison J. The information-seeking behaviour of doctors: a review of the evidence. Health Info Libr J. 2007;24:78-94.

27. Jayaratne YS, Anderson NK, Zwahlen RA. Readability of websites containing information on dental implants. Clin Oral Implants Res. 2014;25:1319-24

28. Petersen PE. Oral cancer prevention and control-The approach of the world health organization. Oral Oncol. 2009;45:454-60.

29. Seoane-Lestón J, Velo-Noya J, Warnakulasuriya S, Varela-Centelles P, Gonzalez-Mosquera A, Villa-Vigil MA, et al. Knowledge of oral cancer and preventive attitudes of Spanish dentists. Primary effects of a pilot educational intervention. Med Oral Patol Oral Cir Bucal. 2010;15:e422-6.

\section{Conflict of interest}

None declared.

Acknowledgments

Leonardo Da Vinci Project (Awaredent-2) (2012-1-GR1-10427 4). 